\title{
Survival of the fittest: retrospective cohort study of the longevity of Olympic medallists in the modern era
}

\author{
Philip M Clarke professor ${ }^{1}$, Simon J Walter research fellow ${ }^{1}$, Andrew Hayen associate professor ${ }^{2}$, \\ William J Mallon orthopaedic surgeon ${ }^{3}$, Jeroen Heijmans technical adviser ${ }^{4}$, David M Studdert \\ professor $^{1}$
}

${ }^{1}$ Melbourne School of Population Health, University of Melbourne, Parkville, VIC 3052, Australia; ${ }^{2}$ School of Public Health and Community Medicine, University of New South Wales, Sydney, Australia; ${ }^{3}$ Triangle Orthopaedic Associates, Durham, NC, USA; ${ }^{4}$ Software Improvement Group (SIG), Amsterdam Bleekstraat 70c 3134 EB Vlaardingen, Netherlands

\begin{abstract}
Objective To determine whether Olympic medallists live longer than the general population.

Design Retrospective cohort study, with passive follow-up and conditional survival analysis to account for unidentified loss to follow-up.

Setting and participants 15174 Olympic athletes from nine country groups (United States, Germany, Nordic countries, Russia, United Kingdom, France, Italy, Canada, and Australia and New Zealand) who won medals in the Olympic Games held in 1896-2010. Medallists were compared with matched cohorts in the general population (by country, age, sex, and year of birth).
\end{abstract}

Main outcome measures Relative conditional survival.

Results More medallists than matched controls in the general population were alive 30 years after winning (relative conditional survival 1.08, 95\% confidence interval 1.07 to 1.10 ). Medallists lived an average of 2.8 years longer than controls. Medallists in eight of the nine country groups had a significant survival advantage compared with controls. Gold, silver, and bronze medallists each enjoyed similar sized survival advantages. Medallists in endurance sports and mixed sports had a larger survival advantage over controls at 30 years $(1.13,1.09$ to $1.17 ; 1.11,1.09$ to 1.13) than that of medallists in power sports $(1.05,1.01$ to 1.08$)$.

Conclusions Olympic medallists live longer than the general population, irrespective of country, medal, or sport. This study was not designed to explain this effect, but possible explanations include genetic factors, physical activity, healthy lifestyle, and the wealth and status that come with international sporting glory.

\section{Introduction}

Pierre de Coubertin, founder of the modern Olympics, introduced the Olympic motto "citius, altius, fortius" (swifter, higher, stronger) to describe the sporting aspirations of athletes. ${ }^{1}$ It is also an apt description of Olympians, who represent the pinnacle of human fitness and physical achievement. Do Olympians enjoy longer life?

There are no large scale published studies of the longevity of Olympians, and the evidence on whether elite athletes live longer is mixed. ${ }^{2}$ German international soccer players were recently shown to have a shorter life expectancy than matched men from the general population. ${ }^{3}$ Studies of Danish athletic champions, ${ }^{4}$ New Zealand international rugby players, ${ }^{5}$ and US major league baseball players ${ }^{6}$ have found no differences, and an early review of the literature reached the same conclusion. ${ }^{7}$ By contrast, analyses of Polish Olympians, ${ }^{8}$ the Italian national track and field team, ${ }^{9}$ major league baseball players, ${ }^{10}$ and selected tennis champions and Olympic medallists in several sports and years ${ }^{11}$ have identified survival advantages compared with the general population. Studies of Finnish athletes in various sports found lower standardised mortality ratios among competitors in endurance, team, and "mixed" sports, but not among competitors in "power" sports. ${ }^{12}{ }^{13}$ Most research has focused on athletes from one country in a particular sport.

Since the modern Olympic era began in 1896, nearly 25000 athletes competing under 136 different flags have won medals. Most medallists come from a small number of countries, including the United States, Germany, Russia, and United Kingdom. We compared the longevity of these medallists to a matched cohort of their compatriots from the general population. 


\section{Methods \\ Data sources}

The OlyMADMen, an international consortium of Olympic historians and statisticians, has collected data since the 1980s on all Olympians. Much early data came from primary research conducted for books ${ }^{14}{ }^{15}$ coauthored by one author of the present study (WJM), a member of OlyMADMen and former president and cofounder of the International Society of Olympic Historians. OlyMADMen is widely regarded as the most authoritative source of information on Olympians. The International Olympic Committee (IOC) has used information from the OlyMADMen database to complete its official archives.

The OlyMADMen database draws on various sources. Names and demographic information are obtained from official competitor lists. Biographical information is complemented with data from national Olympic historians, as well as official sources such as birth registers. Information on events and placings comes from official reports and results from each Olympics, supplemented with magazines and newspapers for the early years. Information on Olympians' deaths is obtained from friends and relatives, internet searches, international professional sporting clubs and bodies, and published obituaries. Since 2008, a form of the database was made available online, ${ }^{16}$ allowing Olympians, their friends and relatives, and other visitors to advise on corrections and additions.

\section{Study variables and sample}

The OlyMADMen database contains information on 118442 athletes who participated in the 27 summer and 21 winter games held from the first modern Olympics in Athens in 1896 to Vancouver in 2010. (At the time of data extraction for our study, the OlyMADMen database did not include information on medallists from the 2012 Games in London.) Variables in the database included Olympians' sex, birth date, and death date; the year, sports, and events competed; event placings; and countries represented.

One or more medals were won by 24785 athletes competing for 136 different countries and geopolitical entities. However, nine countries or country groups (each with $>850$ medallists) accounted for most Olympic medallists in the modern era $(\mathrm{n}=15$ $820 ; 63.8 \%)$. These groups are: the US, Nordic countries (Denmark, Finland, Iceland, Norway, and Sweden), Russia (the Russian Empire, Soviet Union, and Russia), Germany (the German Empire, Interbellum Germany, East Germany, West Germany, and reunified Germany), UK, France, Italy, Canada, and Australia and New Zealand. We focused the analysis on medallists from these countries.

For Germany and Russia, we restricted the sample to medallists from Olympics after 1950. This was because life table coverage for German medallists was poor during the first and second world wars, which undermined construction of comparator cohorts in the general population. Russia had only a small number of medallists before 1950 .

Medallists who represented more than one country group or competed in more than one sport or games, were classified on their status when they won their first medal. After excluding 214 medallists with missing birthdates, the final study sample consisted of 15174 medallists. Although other variables of interest had trivial numbers of missing values, death dates posed an analytical challenge.

\section{Ascertainment of death dates}

An absent date of death generally indicated that a medallist was alive, but some deaths could have been missed. OlyMADMen monitors Olympian deaths, although some loss to follow-up is inevitable with irregular contact with cohort members. ${ }^{17} \mathrm{We}$ could not identify who was lost to follow-up, yet this had to be accounted for in the survival analysis to avoid overestimating survival.

\section{Accounting for unidentified loss to follow-up among medallists}

We used a technique described by Tallis and colleagues, ${ }^{17}$ which conditions survival on death before a specified number of years of follow-up (in our analyses, we chose 60 years). This conditional approach to survival analysis is unaffected by unidentified loss to follow-up, provided the losses are independent of follow-up time and model covariates. If either of these conditions is not met, the approach is still reliable as long as unidentified loss to follow-up does not exceed 10-15\% of the cohort. ${ }^{17}$

Although loss to follow-up in our cohort was unknown, it was unlikely to exceed $10-15 \%$. An estimate can be derived by analysing death dates recorded for medallists up to and including the summer games and winter games of 1928. OlyMADMen run a project tracking the oldest Olympians, and there is believed to be only one living competitor from this period. Records for the first four modern games $(1896,1900,1904,1906)$ were less complete than later years, and $121(18 \%)$ medallists did not have recorded death dates. For the next seven games (summer 1908, 1912, 1920, 1924, 1928; winter 1924, 1928), 128 (5\%) medallists had no date of death. Overall, these early games averaged $8 \%$ loss to follow-up.

\section{Life tables}

To assess medallists' longevity, we used comparators from life tables for the general population. We obtained period life tables for the nine country groups from publicly available sources. The life tables had excellent coverage of the modern Olympic era (web appendix).

Each medallist was matched by birth year, sex, and age to the life table of the country they represented. We then constructed a survival curve for each "average comparator" in the general population by tracking their hazard from year to year across the period life tables (that is, converting period life tables to cohort life tables). Next, we constructed an overall comparator survival curve by combining ${ }^{18}$ individual curves derived from general populations.

\section{Statistical analysis}

Our analyses compared survival among medallists with that among corresponding cohorts from the general population. Relative survival was defined as actual survival among medallists divided by their expected survival (based on survival of the general population cohorts). Because we used Tallis and colleagues' method to adjust for unidentified loss to follow-up, ${ }^{17}$ we reported relative survival that was conditional on death occurring within 60 years of the first medal won. We used an approach based on Fieller's theorem to obtain confidence intervals. ${ }^{19}$

To quantify the additional life expectancy of medallists, we computed conditional survival curves for the medallist and general population cohorts, and took the difference of the area under each curve. To avoid immortal time bias, ${ }^{20}$ survival 
estimates for each medallist began from the winning of their first medal, which was not necessarily their first Olympics.

After calculating the overall relative conditional survival for medallists, we examined relative survival by country group, medal, and sport. The sports analysis focused on a subsample of $4583(30 \%)$ medallists grouped into categories used by Kujala and colleagues in a 2001 analysis of Finnish athlete longevity, ${ }^{13}$ specifically: endurance (long distance running, cross country skiing), mixed (soccer, ice hockey, basketball, track and field jumping, short distance running), and power (weightlifting, wrestling, boxing, track and field throwing).

\section{Results}

Medallists were mostly men and had a mean age of 26 years (table $\Downarrow$ ). The nine country groups that produced the most medallists accounted for $64 \%$ of all medallists. By 15 March 2012, 5095 (34\%) medallists had died.

Figure $1 \Downarrow$ reports the survival of medallists from the nine country groups relative to the general population. At 10 years, $2 \%$ more of the medallist cohort were alive; at 30 years, $8 \%$ more of the medallist cohort were alive (relative conditional survival $1.02,95 \%$ confidence interval 1.01 to $1.02 ; 1.08,1.07$ to 1.09 ). On average, medallists lived 2.8 years longer.

This survival advantage occurred in eight country groups, although the size of the advantage varied (fig $2 \Downarrow$ ). At 30 years, medallists from Russia (relative conditional survival 1.18, 95\% confidence interval 1.16 to 1.20$)$, France $(1.10,1.05$ to 1.15$)$, Italy $(1.07,1.03$ to 1.11$)$, Australia and New Zealand (1.06, 1.01 to 1.11$)$, Germany $(1.05,1.03$ to 1.06$)$, Nordic countries $(1.05,1.03$ to 1.08$)$, and the UK $(1.04,1.00$ to 1.08$)$ had a survival advantage over their matched compatriots. The survival advantage of Canadian medallists at 30 years over the general population was not significant $(1.04,0.99$ to 1.08$)$.

Grouping Olympians by the type of medal won showed similar survival advantages for gold, silver, and bronze medallists (fig $3 \Downarrow$ ). At 30 years, Olympic medallists in endurance sports (relative conditional survival $1.13,95 \%$ confidence interval 1.09 to 1.17$)$ and mixed sports $(1.11,1.09$ to 1.13$)$ had a larger survival advantage over the general population than did those in power sports $(1.05,1.01$ to 1.08 ; fig 3$)$.

\section{Discussion}

In this study of Olympic medallists from nine country groups that have won the most medals, medallists averaged longer lifespans, compared with matched cohorts in the general population. This advantage was significant in eight of the nine country groups examined, and across different types of medals and sports.

\section{Comparison with other studies}

Our findings broadly accord with other studies identifying survival advantages among elite athletes. ${ }^{8-13}$ Although some studies have found longevity not to differ between athletes and the general population, ${ }^{4-6}$ most of these studies are older and tracked athletes who competed in the first half of the twentieth century, which may explain the discrepancy in findings.

A review by Teramoto and Bugnum ${ }^{2}$ raises another possible explanation for conflicting results in studies of elite athletes' longevity. Athletes in some types of sport (such as endurance) have longer than average lifespans, while those in other sport types do not. Our sport subanalyses mimicked categories used in a 2001 study, ${ }^{13}$ which found that elite Finnish athletes in endurance and mixed sports lived longer than the general population, but athletes in power sports did not. We found medallists in all three categories to have a survival advantage. Our study had a larger sample, included athletes from many countries, used a different analytical method, and focused on Olympic medallists only

\section{Interpretation of findings}

Why do Olympic medallists live longer? Our study aimed to test whether medallists' had a survival advantage, not to identify reasons for this, so the following explanations are speculative. One explanation is that athletes are much healthier than the average person. Part of this advantage could be genetic, but environmental factors undoubtedly amplify genetic advantages. Young athletes who exhibit exceptional physical talents are often selected into national training squads to undergo intensive physical training over many years. Most Olympic medallists will have come through such programmes.

Strong evidence indicates that physical activity confers many health benefits, including improved functional health status and reduced risks of cardiovascular disease, coronary heart disease, stroke, depression, type 2 diabetes, and breast and colon cancer. ${ }^{2122}$ Studies of the relation between all cause mortality and physical activity generally show large reductions in mortality risk with low to moderate levels of activity, and small additional reductions at high activity levels. ${ }^{21}$ The physical activity and fitness of elite athletes are usually at the extreme end of the spectrum. Thus, they should at least enjoy the survival advantages linked to vigorous exercise.

Nonetheless, for most elite athletes, the period spent training intensively and competing occupies a minority of their life.

Surveys of retired Finnish athletes, including Olympians, have shown lower than average rates of smoking, ${ }^{23-25}$ ischaemic heart disease and diabetes, ${ }^{26}$ and depression and anxiety, ${ }^{25}$ but possibly higher rates of musculoskeletal conditions such as osteoarthritis. ${ }^{23} 26$ These former athletes also seemed to remain physically active.

Another explanation relates to the wealth and fame that international sporting success confers on many medallists. Evidence strongly indicates that higher socioeconomic status is associated with lower mortality. ${ }^{27}$ Improved nutrition, education, and access to medical services all mediate this effect. ${ }^{28}$ The influence of social status on mortality risk, independent of wealth, is more controversial, although many studies have identified such an effect. ${ }^{29}$ Unlike other studies that have examined relative survival among celebrities of varying degrees of fame, ${ }^{30}$ we observed no clear longevity differences by medallists' stature; similar survival advantages were observed among gold, silver, and bronze medallists.

\section{Study strengths and weaknesses}

A major strength of our study was its scale; we used comprehensive data for many elite athletes from various populous countries over 115 years. However, we could not identify exactly how many and which deaths were missed among medallists after 1930. Instead, we used a form of relative survival that is robust to systematic unidentified loss to follow-up, provided that the proportion lost is moderate. However, if the loss in our sample substantially exceeded that observed in early years and varied systematically over time, this method could have underestimated or overestimated relative conditional survival.

By examining relative survival by country, medal, and sport—our study provided limited evidence that the advantage 
was somewhat durable, but it was not designed to explain why medallists live longer. We did not have information on causes of death, medallists' health related behaviours, or lifestyle factors (including drug and alcohol use) relative to the general population. Therefore, we could not adjust our results for these variables.

Finally, our analysis compared Olympic medallists with the general population. Athletes generally, not merely the elite, could have similar survival advantages. Isolating a pure "Olympic effect" would need a different study design-for instance, comparing the longevity of high performing athletes who do not make it to the Olympics with those who do.

\section{Conclusion}

The elite warrior Achilles in Greek mythology was forced to choose between a short glorious life and a long obscure one. ${ }^{3}$ There is no such trade off for Olympic medallists.

\section{We thank the OlyMADMen.}

Contributors: PMC came up with the study idea; contributed to the study design, analyses, preparation, and design of exhibits; and cowrote the first draft of the manuscript with DMS. SJW and AH contributed to the study design, analyses, preparation of exhibits, and writing of methods and results. WJM and $\mathrm{JH}$ collected and assembled the study dataset, assisted in data interpretation, and contributed to the manuscript writing. DMS developed the study idea with PMC; contributed to the study design, data interpretation, and design of exhibits; conducted the literature review; and cowrote the first draft of the manuscript (with PMC).

\section{Funding: None.}

Competing interests: All authors have completed the ICMJE uniform disclosure form at www.icmje.org/coi_disclosure.pdf (available on request from the corresponding author) and declare: no support from any organisation for the submitted work; no financial relationships with any organisations that might have an interest in the submitted work in the previous three years; no other relationships or activities that could appear to have influenced the submitted work.

Data sharing: Data for Olympians used to construct the study sample are available from Bill Mallon of the OlyMADMen (bill1729@gmail.com).

Mallon B, Heijmans J. Historical dictionary of the Olympic movement. 4th ed. Scarecrow Press, 2011.

2 Teramoto M, Bungum TJ. Mortality and longevity of elite athletes. J Sci Med Sport 2010;13:410-6.
3 Kuss O, Kluttig A, Greiser KH. Longevity of soccer players: an investigation of all German internationals from 1908 to 2006. Scand J Med Sci Sports 2010;13:410-6.

4 Schnohr P. Longevity and causes of death in male athletic champions. Lancet 1971;2:1364-6.

5 Beaglehole R, Stewart A. The longevity of international rugby players. NZ Med J 1983;96:513-5.

6 Waterbor J, Cole P, Delzell E, Andjelkovich D. The mortality experience of major-league baseball players. N Engl J Med 1988:318:1278-80.

7 Yamaji K, Shephard RJ. Longevity and causes of death of athletes. J Hum Ergol (Tokyo) 1977;6:15-27.

8 Gajewski AK, Poznańska A. Mortality of top athletes, actors and clergy in Poland: 1924-2000 follow-up study of the long term effect of physical activity. Eur J Epidemiol 2008;23:335-40.

9 Menotti A, Amici E, Gambelli GC, et al. Life expectancy in Italian track and field athletes. Eur J Epidemiol 1990;6:257-60.

10 Saint Onge JM, Rogers RG, Kreuger PM. Major league baseball players' life expectancies. Soc Sci Q 2008;89:817-30

11 Coate D, Sun R. Survival estimates for elite male and female Olympic athletes and tennis championship competitors. Scand J Med Sci Sports 2012, doi:10.1111/j.1600-0838.2012. 01449.

12 Sarno S, Sahi T, Koskenvuo M, Kaprio J. Increased life expectancy of world class male athletes. Med Sci Sports Exerc 1993;25:237-44

13 Kujala UM, Tikkanen HO, Sarna S, Pukkala E, Kaprio J, Koskenvuo M. Disease-specific mortality among elite athletes. JAMA 2001;285:44-5.

14 Kamper E, Mallon B. The golden book of the Olympic Games. Vallardi and Associati, 1992.

15 Mallon B. Total Olympics: the complete record of every event in every Olympics. Total Sports, 2001.

16 SR Olympic Sports. Olympics statistics and history. 2012. www.sports-reference.com/ olympics/.

17 Tallis GM, Leppard P, O'Neill TJ. The analysis of survival data from a central cancer registry with passive follow-up. Stat Med 1988;7:483-90.

18 Hakulinen T. Cancer survival corrected for heterogeneity in patient withdrawal. Biometrics 1982;38:933-42.

19 Fieller EC. Some problems in interval estimation. J R Stat Soc B 1954;B16:175-85.

20 Sylvestre M, Huszti E, Hanley JA. Do Oscar winners live longer than less successful peers? A reanalysis of the evidence. Ann Intern Med 2006;145:361-3.

21 Physical Activity Guidelines Advisory Committee Report, 2008. US Department of Health and Human Services, 2008.

22 Warburton DER, Nicol CW, Bredin SSD. Health benefits of physical activity: the evidence. CMAJ 2006;174:801-9.

23 Kujala UM, Sarna S, Kaprio J, Koskenvuo M. Hospital care in later life among former world-class Finnish athletes. JAMA 1996;276:216-20.

24 Alaranta A, Alaranta H, Patja K, Palmu P, Prättälä R, Martelin T, et al. Snuff use and smoking in Finnish olympic athletes. Int J Sports Med 2006;27:581-6.

25 Backmand H, Kaprio J, Kujala U, Sarna S. Influence of physical activity on depression and anxiety of former elite athletes. Int J Sports Med 2003;24:609-19.

26 Sarna S, Kaprio J, Kujala UM, Koskenvuo M. Health status of former elite athletes. The Finnish experience. Aging (Milano) 1997;9:35-41.

27 Smith JP. Healthy bodies and thick wallets: the dual relation between health and economic status. J Econ Perspect 1999:13:145-66.

28 Cutler D, Deaton A, Lleras-Muney A. The determinants of mortality. J Econ Perspect 2006;20:97-120.

29 Marmot MG, Wilkinson RG. Social determinants of health. 2nd ed. Oxford University Press, 2005.

30 Redelmeier DA, Singh SM. Survival in Academy Award-winning actors and actresses. Ann Intern Med 2001:134:955-62.

31 Homer. The lliad. Penguin Books, 1998.

Accepted: 16 November 2012

Cite this as: BMJ 2012;345:e8308

(c) BMJ Publishing Group Ltd 2012 


\section{What is already known on this topic}

Evidence on whether elite athletes live longer is mixed and whether Olympic medallists do so is not known

\section{What this study adds}

Olympic medallists live longer than the general population, irrespective of country, medal, or sport

Possible explanations include genetic factors, physical activity, healthy lifestyle, and the wealth and status that come with international sporting glory

\section{Table}

\section{Table 1| Characteristics of Olympic medallists, 1896-2010*}

No $(\%)$ of medallists $(n=15174)$

\begin{tabular}{|c|c|}
\hline Demographics & \\
\hline Male & $11619(77)$ \\
\hline Age at competition, mean (SD) & $26(6)$ \\
\hline Deceased & $5095(34)$ \\
\hline Medal type & \\
\hline Gold & $5180(34)$ \\
\hline Silver & 4925 (32) \\
\hline Bronze & $5069(33)$ \\
\hline Country group & \\
\hline US & $3410(22)$ \\
\hline Nordic countries & $2619(17)$ \\
\hline Russia/former Soviet Union† & $2181(14)$ \\
\hline Germany & $1906(13)$ \\
\hline UK & $1305(9)$ \\
\hline France & $1048(7)$ \\
\hline Italy & $957(6)$ \\
\hline Canada & $879(6)$ \\
\hline Australia and New Zealand & $869(6)$ \\
\hline Sports & \\
\hline Athletics & $1782(12)$ \\
\hline Rowing & $1515(10)$ \\
\hline Swimming & $1032(7)$ \\
\hline Ice hockey & $915(6)$ \\
\hline Gymnastics & $770(5)$ \\
\hline Sailing & $709(5)$ \\
\hline Cycling & $593(4)$ \\
\hline Fencing & $530(3)$ \\
\hline Football & $513(3)$ \\
\hline Other & $6815(45)$ \\
\hline Olympic season & \\
\hline Summer & $12660(83)$ \\
\hline Winter & $2514(17)$ \\
\hline Olympic periods & \\
\hline 1896-1928 (9 summers, 2 winters) & $3222(21)$ \\
\hline $1932-60$ ( 6 summers, 6 winters) & $2781(18)$ \\
\hline 1964-88 (7 summers, 7 winters) & $4876(32)$ \\
\hline $1992-2010$ ( 5 summers, 6 winters) & $4295(28)$ \\
\hline
\end{tabular}




\section{Figures}

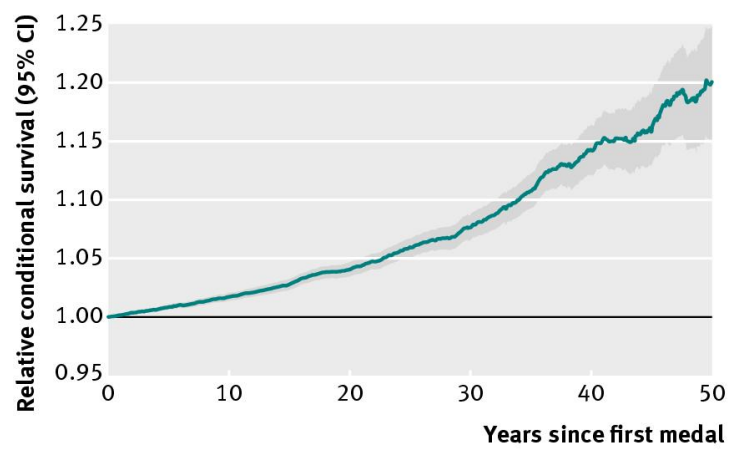

Fig 1 Survival of Olympic medallists from selected countries relative to the general population, 1896-2012
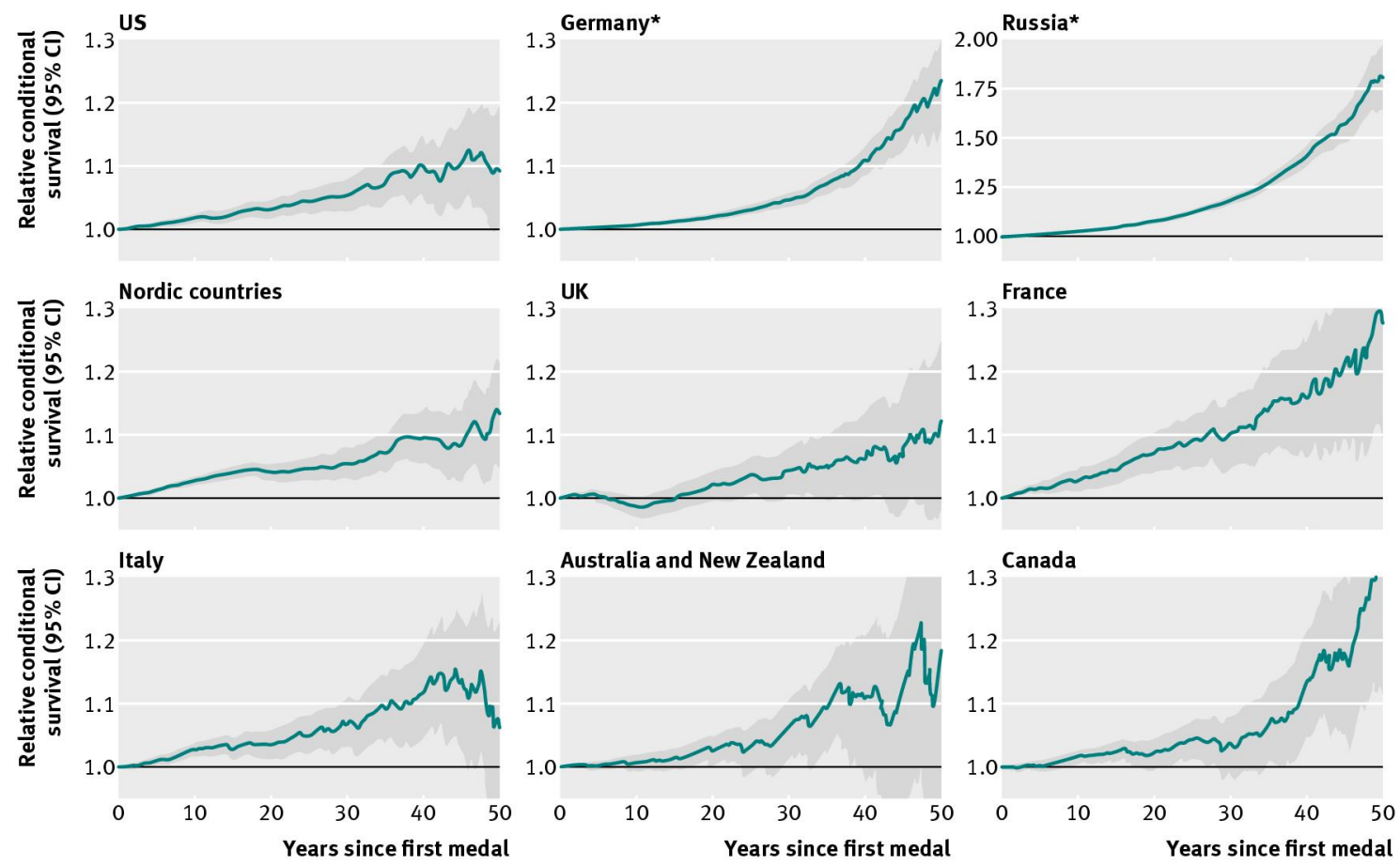

Fig 2 Survival of Olympic medallists, by country group. *Excludes medallists from Olympic Games before 1950 

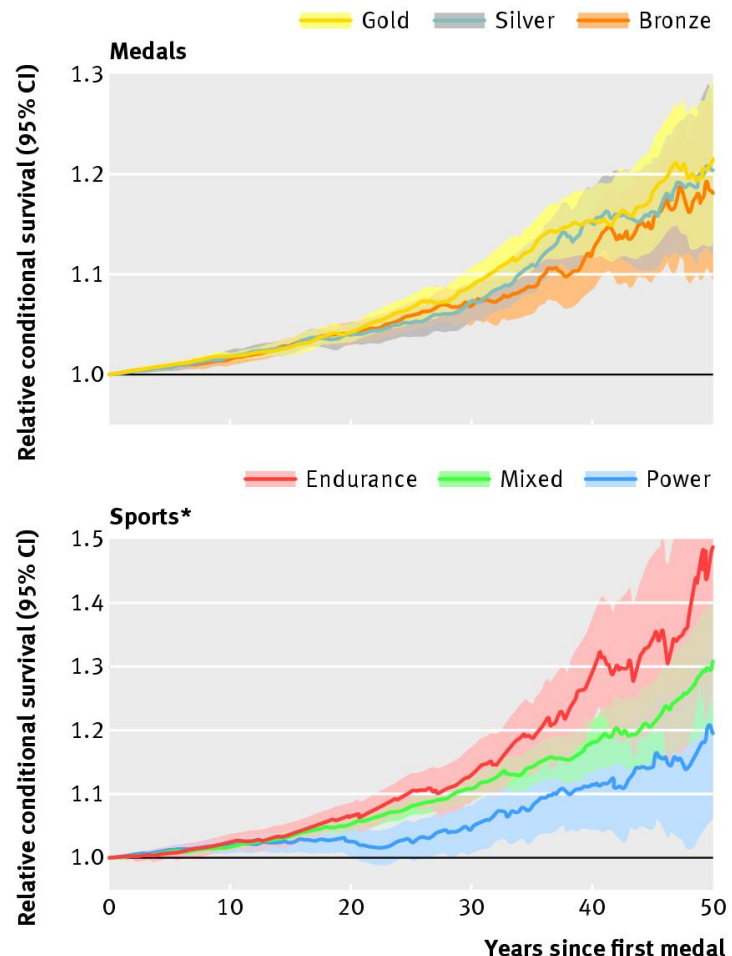

Fig 3 Survival of Olympic medallists by medal and sport. *Analysis based on subsample (30\%) of all medallists from the nine country groups 